College of Business
and Public Policy
UNIVERSITY of ALASKA ANCHORAGE
Department of Economics Working Paper
WP 2014-01
April 2014
Price Controls and Banking in Emissions Trading:
An Experimental Evaluation

Jniversity of Massachusetts Amherst
James J. Murphy
Nankai University, Tianjin, China
University of Alaska Anchorage
John M. Spraggon
University of Massachusetts Amherst

UAA DEPARTMENT OF ECONOMICS

3211 Providence Drive

Rasmuson Hall 302

Anchorage, AK 99508

http://econpapers.uaa.alaska.edu/ 


\title{
Price Controls and Banking in Emissions Trading: An Experimental Evaluation
}

\author{
Abstract: We present results from laboratory emissions markets designed to investigate the \\ effects of price controls and permit banking on limiting permit price risk. While both instruments \\ reduce between-period price volatility and within-period price dispersion, combining price \\ controls and permit banking yields important benefits. Banking alone produces high permit \\ prices in earlier periods that fall over time, but the combined policy produces lower initial prices \\ and lower volatility. However, banking, price controls, and the combination all produce higher \\ between-period emissions volatility. Hence, for emissions markets that seek to control flow \\ pollutants with strictly convex damages, efforts to limit permit price risk can result in higher \\ expected damage.
}

Keywords: Emissions trading, Cap and trade, Laboratory experiments, Permit markets, Permit banking, Price controls, Price collars

JEL Codes: C91, L51, Q58

\section{Introduction}

The highly uncertain costs of controlling greenhouse gas emissions have generated significant research and policy innovation in modifying emissions markets to contain abatement costs and limit permit price risk. While several methods for doing so have been proposed, the two most important are giving firms the ability to bank emissions permits and implementing permit price 
controls. ${ }^{1}$ In this paper we provide results from a series of laboratory emissions permit markets that were designed to evaluate the relative effectiveness of these methods in terms of limiting permit price risk.

Permit banking allows firms to shift abatement across time in a cost-effective manner and to hedge against permit price risk associated with uncertain abatement costs, uncertain emissions, and other stochastic elements (Rubin 1996, Schennach 2000). Imposing a permit price ceiling and floor on emission trading — a so-called price collar — is a more direct way of limiting price volatility. ${ }^{2}$ It is well known that an optimal hybrid policy of price controls and emission trading is never less efficient, and is often more efficient, than a pure trading program (Roberts and Spence 1976). Some analyses of price controls only involve price ceilings, or safety valves (Pizer 2002, Jacoby and Ellerman 2004), but several simulation studies have demonstrated the costeffectiveness of combining price ceilings and price floors (Burtraw et al. 2010, Fell and Morgenstern 2010, Philibert 2008). ${ }^{3}$

Most existing emissions trading programs allow some form of permit banking, and many recent proposals to control greenhouse gases also include some form of price control. (See Hood 2010 and Newell et al. 2013 for several examples). However, little work has been done to

\footnotetext{
${ }^{1}$ Fell et al. (2011) provide a recent literature review on alternative cost-containment approaches.

${ }^{2}$ Prices in existing permit markets can be fairly volatile. Pizer (2005) presents time series of permit prices that illustrate this volatility in the RECLAIM program and the $\mathrm{NO}_{\mathrm{X}}$ Budget Trading program. Nordhaus (2007, pg. 38) estimates average volatility in the $\mathrm{SO}_{2}$ Allowance Trading program between 1995 and 2006 and finds that it exceeds the volatility of the consumer price index and the volatility of the stock price index for the Standard and Poor 500 by significant amounts, and approaches the volatility of crude oil prices.

${ }^{3}$ Recent theoretical papers that examine emissions markets with price controls and other cost-containment measures include Weber and Neuhoff (2010), Webster et al. (2010), and Grull and Taschini (2011), and Stranlund and Moffitt (2013).
} 
examine the combined effects of price controls and permit banking, perhaps because of the lack of field data. Exceptions include Fell and Morgenstern (2010) and Fell et al. (2012) who conducted numerical simulations of a U.S. cap-and-trade policy for carbon dioxide with permit banking and alternative forms of price control. While numerical simulations of proposed policies provide important information about their potential performance, they are typically based on idealized behavioral and informational assumptions. Economic experiments can complement numerical simulations when field data are lacking by highlighting actual behavior under specific regulations in controlled environments.

Several studies have used experiments to study banking behavior in laboratory emissions markets. Permit banking tends to reduce permit price volatility (Godby et al. 1997, Cason and Gangadharan 2006), but subjects are not always able to exploit the potential gains from banking (Muller and Mestelman 1998). No one to our knowledge has used laboratory experiments to investigate the performance of emission markets with the combination of banking and price controls. $^{4}$

In our experiments, subjects participated in a market for a limited number of permits that allowed them to produce a fictitious good. Uncertainty about future production payoffs provided the motivation for permit banking and the justification for price controls. ${ }^{5}$ We utilized a $2 \times 2$

\footnotetext{
${ }^{4}$ We are aware of only one other experimental study of price controls in emissions markets. Perkis et al. (2012) investigate alternative price ceiling designs. They do not examine the performance of price collars (the combination of price ceilings and floors) nor do they consider permit banking.

${ }^{5} \mathrm{We}$ are not aware of other laboratory experiments in which banking is motivated by uncertain production benefits. Stranlund et al. (2011) and Cason et al. (1999) motivated banking with a reduction in the supply of emissions permits in the middle of multi-period trading sessions. Cason and Gangadharan's (2006) experiments involved stochastic emissions, while subjects in Godby et al. (1997) were motivated by both stochastic emissions and a
} 
design (with/without banking $\times$ with/without price controls). In the two treatments with permit banking, subjects could save as many permits as they wished in a period, but could not borrow permits from future allocations. In the two treatments with price controls, subjects could buy an unlimited number of additional permits at a price ceiling, and could sell an unlimited number at a price floor. The treatment that did not allow banking and did not include price controls serves as a baseline. This design allows us to determine the independent contributions of both banking and price controls to permit market performance.

We analyze the effects of price controls, banking, and the combination on price levels, between-period price volatility (the variation in prices over time), within-period price dispersion (the distribution of trading prices within a period), aggregate emission levels, and emissions volatility (the variation in aggregate emissions over time). Permit price volatility can delay investment in abatement technologies and increase abatement costs over time (Zhao 2003). Moreover, dynamically efficient control of a uniformly mixed pollutant requires that abatement responsibilities be distributed to minimize within-period aggregate abatement costs, which in turn requires a consistent price signal (Kling and Rubin 1997). Hence, high price dispersion can limit the ability of emissions markets to allocate individual abatement responsibilities efficiently. On the other hand, banking and price controls make the level of aggregate emissions in a period endogenous, so these provisions can affect the environmental performance of emissions markets. For example if a price ceiling is set too low, or if firms over-use this feature, then price controls 
can lead to increased aggregate emissions and environmental damage. ${ }^{6}$ In addition, containing price volatility can lead to increased volatility in aggregate emissions. Given a level of accumulated emissions over some time interval, increased emissions volatility does not affect expected environmental damage if the pollutant is a stock pollutant and there is no threat of exceeding a threshold that triggers a large increase in damages. However, if emissions produce a flow pollutant with a strictly convex damage function, then increased emissions volatility produces higher expected damage.

Our efforts yield several new results that have important implications for designing emissions markets, including:

1. Both permit banking and price controls reduce within-period price dispersion and between-period price volatility. Thus, both instruments promote permit price consistency and stability. Moreover, the combination of banking and price controls leads to significantly less price volatility than either instrument alone.

2. Permit banking alone tends to lead to high permit prices in early periods that fall over time as subjects build up permit banks and then draw them down. This is consistent with a theoretical model of a policy that allows firms to save permits for the future but does not allow borrowing (Schennach 2000). Subjects build up permit banks to guard against

\footnotetext{
${ }^{6}$ Debates concerning price controls have highlighted the concern that they can lead to emissions exceeding the goals of a cap-and-trade policy. To address these concerns for a price ceiling, Murray et al. (2009) proposes a fixed reserve of permits that could be sold at the price ceiling in a period. Fell et al. (2012) examine the efficiency and environmental integrity of so-called "soft" price controls, which allow limited purchases of additional permits at the price ceiling and limited sales at the price floor. They show that while soft controls effectively limit the chance that emissions will exceed targets, they are less efficient than controls that do not impose such restrictions. Our experiments do not impose these restrictions.
} 
the possibility of future bank shortages and then draw down these banks as the continuation of the policy becomes uncertain.

3. Combining price controls with banking leads to lower initial prices and a flatter time series. Our theoretical model and experimental results suggest that this is mainly due to the price ceiling suppressing permit prices in early periods. ${ }^{7}$ The price floor also plays a role in smoothing the price series because it holds up prices in later periods.

4. In our environment, the cost containment measures do not have a significant impact on aggregate emissions over time. However, we confirm a fundamental tradeoff between reduced price volatility and higher emissions volatility: banking, price controls, and the combination each reduce permit price volatility in exchange for significantly higher emissions volatility.

The remainder of the paper proceeds as follows. In the next section we provide a theoretical model of permit banking and price controls under uncertainty. In section 3 we describe our experiments, and report the results of the experiments in section 4 . We conclude in section 5 .

\section{A model of permit banking and price controls under uncertainty}

In this section we sketch a model of emissions permit banking with price controls under uncertainty about firms' costs of controlling emissions. The model is similar to those in Fell and Morgenstern (2010) and Fell et al. (2012), who use their models to conduct simulations of the

\footnotetext{
${ }^{7}$ This result confirms speculation by Jacoby and Ellerman (2004, subsection 4.1) that a price ceiling is likely to be most effective in the early stages of a new permit program with banking because a stock of permits to dampen uncertainty would take some time to build up and initial banking to build up this stock would raise prices.
} 
control of carbon dioxide in the US. In contrast, we use the model to draw qualitative conclusions about the time paths of permit prices, emissions and banking to determine whether behavior in our experiments is consistent with the theory.

An industry is allocated $L_{t}$ emissions permits in a period $t$ and industry emissions during the period are $Q_{t}$. Competitive trade in permits generates a price $p_{t}$. It is well known that competitive permit trading results in maximizing within-period industry profit given the industry holds its aggregate emissions to $Q_{t}$ (Rubin 1996). This allows us to model dynamic permit trading from the perspective of the industry as in Schennach (2000). Let $B\left(Q_{t}, u_{t}\right)$ be maximum industry profit given $Q_{t}$ emissions, with $B_{Q}\left(Q_{t}, u_{t}\right)>0$ and $B_{Q Q}\left(Q_{t}, u_{t}\right)<0$. The variable $u_{t}$ captures random industry-wide shocks that affect profits. This variable is unknown in periods before $t$, but is revealed at the beginning of $t$.

The emissions market includes a price ceiling and price floor. To implement the price controls the government commits to selling an unlimited number of additional permits at an exogenous price $p_{t}^{c}$, and it commits to purchasing as many permits as the industry wishes to sell at price $p_{t}^{f}$. Let $y_{t}^{c}$ denote industry purchases of additional permits at the price ceiling in $t$, and let $y_{t}^{f}$ denote industry sales of permits to the government at the price floor. The regulation allows firms to bank permits for future use or sale on a one-to-one basis, but it does not allow borrowing against future allocations. The industry's stock of banked permits at the beginning of period $t+1$ is $S_{t+1}$ and the evolution of the aggregate bank of permits between periods is

$$
S_{t+1}=S_{t}+L_{t}-Q_{t}+y_{t}^{c}-y_{t}^{f} \geq 0
$$


In every period there is an exogenous probability that the policy will continue into the next period. Let $\alpha_{t}$ denote the probability that the program continues into period $t$. This feature is motivated by our experimental design for which $\alpha_{t}=1$ in the first ten periods of each session and then $\alpha_{t}<1$ for the remaining periods. ${ }^{8}$ The stochastic terminal date is the only way that our theoretical model differs from previous efforts by Fell and Morgenstern (2010) and Fell et al. (2012).

The time paths of expected emissions, banking, and permit prices can be determined from the stochastic dynamic programming problem of choosing $\left(Q_{0}, Q_{1}, \ldots\right),\left(y_{0}^{c}, y_{1}^{c}, \ldots\right)$ and $\left(y_{0}^{f}, y_{1}^{f}, \ldots\right)$ to maximize the expected present value of industry profits,

$$
E_{0}\left[\sum_{t=0}^{\infty} \alpha_{t}(1+\mu)^{-t}\left(B\left(Q_{t}, u_{t}\right)-p_{t}^{c} y_{t}^{c}+p_{t}^{f} y_{t}^{f}\right)\right],
$$

subject to (1), non-negativity constraints for $y_{t}^{c}$ and $y_{t}^{f}$, and $S_{0}=0$. In (2), $\mu$ is the constant discount rate, and $E_{0}[\cdot]$ denotes the expected value at the beginning of the program.

Market equilibrium in a period requires $B_{Q}\left(Q_{t}, u_{t}\right)=p_{t}$. Thus, given a realization of $u_{t}$, the competitive permit price and aggregate emissions are inversely related. Moreover, given a non-empty bank $S_{t+1}>0$, there is a positive relationship between the current permit price and the size of the bank at the end of the period. That is, a higher price implies reduced emissions and more permits banked. We use the market equilibrium condition in the appendix to show that the

\footnotetext{
${ }^{8}$ Among the several ways we could have chosen to end each experimental session, we opted for a random end date as in Cason and Gangadharan (2006).
} 
relationship between the current permit price in $t$ and the expected permit price $n$ periods ahead can be characterized by

$$
p_{t}=\lambda_{t}+\sum_{s=1}^{n-1}\left(\prod_{s} \alpha_{t+s}(1+\mu)^{-s} E_{t}\left(\lambda_{t+s}\right)\right)+\prod_{s=1}^{n} \alpha_{t+s}(1+\mu)^{-n} E_{t}\left(p_{t+n}\right)
$$

where $\lambda_{\tau} \geq 0, \tau=t, \ldots, t+n$ are the Lagrange multipliers attached to the no-borrowing constraints in every period, and $p_{t}$ and $p_{t+n}$ are constrained by the price controls.

The simplest possible special case of the model is when there is no chance that the program will end in the interval $(t, t+n)$ and there is no chance that the permit bank will be empty in that interval. Then, all the $\alpha$ terms in (3) are equal to $1, E_{t}\left(\lambda_{t+s}\right)=0$ for each $s=0, \ldots, n$, and (3) simplifies to $p_{t}=(1+\mu)^{-n} E_{t}\left(p_{t+n}\right)$. This relationship indicates that the expected price of permits increases at the rate of discount. This Hotelling-type result is standard in the literature on pollution permit banking, and appears to be noted first by Rubin (1996) and Cronshaw and Kruse (1996) under conditions of certainty.

However, Schennach (2000) showed that uncertainty and the prohibition on borrowing permits tends to motivate increased banking in earlier periods to guard against the possibility that the bank will be empty in the future. Continuing to assume that $\alpha_{\tau}=1, \tau=t, \ldots, t+n$, the possibility that the aggregate bank will be empty at some point in the interval $(t, t+n)$ implies

$$
\lambda_{t}+\sum_{s=1}^{n-1}(1+\mu)^{-s} E_{t}\left(\lambda_{t+s}\right)>0
$$

Thus, the restriction on borrowing increases the right side of (3), which implies that $p_{t}$ must also be higher to hold the equality. The higher current permit price is associated with lower emissions and increased permit banking. 
It is also possible that increased banking to guard against future exhaustion of the bank can result in falling expected prices over time. This phenomenon may be particularly relevant for laboratory experiments on banking, because the short length of experimental sessions implies that discounting future payoffs is unlikely. To illustrate falling expected permit prices, continue to assume that $\alpha_{\tau}=1, \tau=t, \ldots, t+n$, but now assume that there is no discounting so that $\mu=0$. In this case (3) simplifies to

$$
p_{t}=\lambda_{t}+\sum_{s=1}^{n-1} E_{t}\left(\lambda_{t+s}\right)+E_{t}\left(p_{t+n}\right)
$$

which indicates $p_{t}>E_{t}\left(p_{t+n}\right)$.

The motivation to hold extra permits to guard against an empty bank can be offset by the possibility the program ends in the future. Note that the right side of (3) is increasing in $\alpha_{t+s}$, $s=0, \ldots, n$, which means that the right side is lower if there is some chance the program ends in the interval $(t, t+n)$. This implies that $p_{t}$ must also be lower, implying higher current emissions and less permit banking. If, as in our experiments, there is an extended period of time in which it is certain that the program will continue, the motivation to save permits to guard against an empty bank is likely to dominate in early periods and then lessen as the continuation of the program becomes uncertain. In the absence of discounting, this suggests a price path that falls over time as a bank of permits is built up in earlier periods and then is drawn down in later periods.

Note from (3) that adding price controls can affect the evolution of permit prices by limiting the current price $p_{t}$, or by limiting the expected future price $E_{t}\left(p_{t+n}\right)$. For example, if price controls reduce expected prices in the future, as might be the case if permit prices rose 
through time, then current prices and current banking are also reduced. On the other hand, if we observe falling prices with banking in the absence of price controls as the discussion above suggests, the addition of a price ceiling might suppress prices in early periods but the price floor might keep prices from falling too far in later periods. If the price ceiling binds in early periods, then initial prices are lower than they would have been in the absence of price controls, resulting in less permit banking in early periods. On the other hand, if the price floor holds up prices in later periods, then we might observe more banking in these periods. Overall, we expect that adding price controls to a program with banking will flatten the permit price path.

\section{Experimental Design and Procedures}

We framed our experiments as a production decision in which a permit was needed to produce a unit of a fictitious good. We chose this neutral frame to avoid potential biases due to individual attitudes about the environment or emissions trading. During each 3-minute period, subjects simultaneously produced units of the good and traded in a discriminative price double auction for permits. Each group consisted of eight individuals evenly divided among four types that differed in terms of production earnings and initial cash and permit allocations. In line with our theoretical model, we introduced uncertainty via random shocks to the subjects' marginal production earnings. There were three possible marginal production earnings schedules for each subject type, Low (L), Medium (M) and High (H), shown in Table 1. Note that these marginal production earning schedules are individual single-period permit demand schedules when firms cannot bank permits. (In the emissions context these can be interpreted as individual marginal abatement cost functions). We will refer to these schedules as permit demand schedules from here on. For each subject type, the different demand schedules are parallel, with the High 
demand schedule being $\mathrm{E} \$ 69$ above the Medium demand schedule for each unit of production and the Low demand schedule being E\$69 below the Medium demand schedule. Subjects knew which demand schedule they faced at the start of each period. In each period of each treatment, a total of 40 permits were supplied to the market. Player types A and B started each round with one permit, and player types $\mathrm{C}$ and $\mathrm{D}$ had an initial permit allocation of nine permits. Subjects also differed in their initial cash endowments. Player types A and B received $\mathrm{E} \$ 3600$ at the start of round one, and E\$2000 at the start of subsequent rounds; player types C and D received $\mathrm{E} \$ 1850$ at the start of round one, and E\$250 at the start of subsequent rounds.

Prior to the experiments we randomly generated four sequences of demand shocks to be applied for each treatment (Table 2). There were four unique sequences. In all treatments, Sequences 1 and 2 were used twice, and Sequences 3 and 4 were used once, for a total of 6 sessions per treatment. Every sequence began with two periods of the Medium demand schedules. Subjects knew this. The purpose was to give subjects an opportunity to bank permits (if allowed) in preparation for the random demand shocks that followed. Starting with the third period, whether the players faced a Low, Medium, or High demand schedule was determined by a role of a die, with each demand level being equally likely. Each sequence lasted at least ten periods with certainty, and this was common knowledge. After the end of round ten and every subsequent period, there was a 5/6 chance that the experiment would continue for another round, determined by the role of a die. To ensure that subjects were aware that the sequences were determined in a truly random fashion, a video of the process was presented during the instructions.

There were four treatments, labeled Baseline, Price Controls (PC), Banking (Bank), and Banking with Price Controls (BankPC). Figure 1 is useful for conveying the differences among 
the treatments. The lines labeled High Demand, Medium Demand, and Low Demand are aggregate permit demand schedules (in the absence of banking) derived from the individual permit demands in Table 1.

The Baseline treatment is a standard market experiment in which production benefits vary by round. Since 40 permits were supplied to the market in every period, competitive permits prices are E\$299 under High Demand, E\$230 under Medium Demand, and E\$161 under Low Demand. The expected price is $\mathrm{E} \$ 230$ because the a priori distribution of demand shocks is symmetric.

The Price Control (PC) treatment adds both a permit price ceiling and price floor to the Baseline treatment. The price controls were set to be symmetric around the expected price of $\mathrm{E} \$ 230$ and to cut the range of competitive prices under the Baseline treatment (E\$161 to E\$299) roughly in half. This led to setting the price ceiling at $\mathrm{E} \$ 265$ and the floor at $\mathrm{E} \$ 195$. We implemented the price ceiling by making an unlimited number of additional permits available for purchase at E\$265. Asks to sell at prices above the ceiling were not accepted, and bids to buy permits at prices greater than E\$265 were filled at E\$265. Existing asks to sell at E\$265 were filled before new permits were issued. The price floor was implemented by allowing subjects to sell as many permits as they wished at $\mathrm{E} \$ 195$. Bids below $\mathrm{E} \$ 195$ were not accepted, and asks to sell at prices below $\mathrm{E} \$ 195$ were filled at $\mathrm{E} \$ 195$. Existing bids to buy permits at $\mathrm{E} \$ 195$ were filled before permits were removed from the market.

Note from Figure 1 that limiting price variation with the price controls produces additional variation in aggregate emissions relative to the fixed level under the Baseline. In particular, when subjects experience the High Demand, the permit price should rise to the ceiling and subjects should produce 52 units, which is 12 more than the initial allocation of 40 . Under 
Low Demand, the price should fall to the price floor and subjects should reduce their production to 24 units (a 16 unit reduction). This is an essential feature of cost-containment measures for emissions markets - efforts to reduce price volatility introduce additional volatility in aggregate emissions.

There were no price controls in the Banking (Bank) treatment. In this treatment, subjects were allowed to save permits for use in the future, but they could not borrow from future permit allocations. Excess permits at the end of an experiment had no redemption value. Banking can reduce volatility in permit prices as subjects save permits in the Low and possibly Medium demand states to use in the High demand state. ${ }^{9}$ To investigate the effects of combining permit banking and price controls, we conducted the Banking with Price Controls (BankPC) treatment, which combined the procedures from the Bank and PC treatments. ${ }^{10}$

A total of 192 subjects were recruited from the general student population at the University of Massachusetts-Amherst. Subjects participated in a training session on one evening and then a data session on a subsequent day. Training consisted of completing a set of instructions and a series of practice periods. For each group, the treatment used in the training session was identical to the data session, but the parameters were different. At the start of the first session, subjects were paid $\$ 5$ for agreeing to participate and showing up on time. They were then given an opportunity to earn additional money in the experiment. Subjects earned experimental dollars $(\mathrm{E} \$)$ that were converted to US dollars at a pre-announced exchange rate. Subjects were paid their combined earnings for both days in cash at the end of the second

\footnotetext{
${ }^{9}$ In the instructions, subjects were informed that their final payoff could be increased by saving permits in Low demand periods for use in High demand periods. This was demonstrated using values that differed substantially from those used in the actual experiments.

${ }^{10}$ The experiment instructions are available upon request.
} 
session. Average earnings in the data sessions ranged between $\$ 15.94$ and $\$ 33.94$, with a mean of $\$ 25.99(\sigma=4.21)$. Sessions lasted approximately 90 minutes.

Our experimental design allows us to test hypotheses concerning the performance of banking provisions and price controls in emissions permit markets. Relative to the Baseline, the theoretical model of the previous section suggests that prices under the Bank treatment should begin relatively high as subjects build up their permit banks to guard against the risk of a bank shortage in the future. Prices should then fall over time as the risk of a bank outage is reduced and the continuation of the program becomes uncertain. If the price controls under the BankPC treatment suppress initial prices, then we should observe lower initial prices that do not fall as rapidly, if at all, and less banking. The price floor may contribute to the smoothing of the permit price path if it holds up prices in later periods.

Relative to the Baseline, giving subjects the ability to bank permits, imposing price controls, and the combination of the two should reduce between-period permit price volatility. We are not as interested in whether price controls or banking are more effective at controlling price volatility, because the answer is sensitive to the specific parameters used. For example, the extent to which price controls limit volatility is likely to be very sensitive to how tight we set the price controls. Instead, we focus on whether price controls and banking are complementary measures for controlling price volatility in the sense that combining these measures leads to lower volatility than either measure alone. Moreover, to the extent that price controls, banking, and the combination are successful at reducing permit price volatility, we should observe significant volatility in aggregate production.

We do not have a priori expectations about the treatment effects on within-period price dispersion, and we are not aware of a theoretical model of emissions permit trading that allows 
for price dispersion to look to for guidance. However, if we observe high price dispersion in the Baseline or Bank treatments, then it is reasonable to expect that the price controls will reduce this dispersion as they truncate the range of possible prices.

Finally, we have clear predictions about the use of the price controls in the absence of banking. All trades in the High demand state should take place at the price ceiling, and all trades in the Low demand state should take place at the price floor. Neither control should be activated in the Medium demand states. We do not have a clear prediction about how often the price controls will be used when they are combined with the ability to bank permits.

\section{Results}

In this section we present the results of our experiments. We begin by analyzing the effects of the different policies on price levels, between-period price volatility, and within-period price dispersion, as well as the use of the price controls in the PC and BankPC treatments. ${ }^{11}$ We then analyze the policy effects on aggregate emission levels and emissions volatility.

For much of the analysis we divide the results into three time intervals, Periods 1-2, Periods 3-9, and Periods 10-13. These breaks are motivated by the experimental design. Recall that there was no uncertainty about permit demand schedules in Periods 1-2. We expected that subjects would use these Medium demand periods in the Bank and BankPC treatments to prepare themselves for future uncertainty. Moreover, recall that for each random sequence of permit demand shocks, starting with period 10 there was a 1/6 chance that the experiment would end

\footnotetext{
${ }^{11}$ Of the 6325 trades across all treatments in periods 1-13, we exclude 7 trades at prices less than E\$30 and another 7 trades at prices above $\mathrm{E} \$ 1000$. None of our qualitative conclusions are affected by omitting these outliers.
} 
after the period was over. Note also that each sequence lasted at least 13 periods. Therefore, our third time interval was Periods 10-13, and the middle interval was Periods 3-9.

\subsection{Prices}

Our analysis of permit prices focuses on treatment and time interval effects on average prices, between-period price volatility, and within-period price dispersion. Average prices, $\bar{p}_{g t}=(1 / I) \sum_{i=1}^{I} p_{i g t}$, are calculated as the mean of all transactions ( $I$ total transactions indexed by $i$ ) for a given group $(g)$ in a given period $(t)$. Price volatility, $\left|\bar{p}_{g t}-\bar{p}_{g, t-1}\right|$, is calculated as the absolute difference in the average price for group $g$ between periods $t$ and $t-1$. Price dispersion, $(1 / I) \sum_{i=1}^{I}\left|p_{i g t}-\bar{p}_{g t}\right|$, is calculated as the mean absolute difference between each trading price and that period's average price.

Unconditional means by treatment and time interval for each of the three variables of interest are provided in Table 3. In Table 4, we also present the results from three linear random effects models of the form $y_{g t}=\alpha_{0}+x_{g t} \beta+v_{g}+\varepsilon_{g t}$. Random effects for each group are $v_{g} \sim N\left(0, \sigma_{v}^{2}\right), \varepsilon_{g t} \sim N\left(0, \sigma_{\varepsilon}^{2}\right)$ is the idiosyncratic error term, and $x_{g t}$ is a vector of independent variables (including interaction terms) for group $g$ in period $t$. The models include dummy variables for treatment, treatment interacted with time interval, and the random sequence of permit demand shocks. We present the results of hypothesis tests of differences between treatments in Tables 5 through 7. 


\subsubsection{Average prices}

The Baseline treatment serves as a control against which the outcomes of the other treatments can be compared. Recall that this treatment consists of a standard discriminative price double auction with a series of independent periods (i.e., permits cannot be banked). Price discovery and convergence to competitive equilibrium prices can be challenging in this environment because aggregate demand may vary each period after period 2. Nevertheless, for each of the three time intervals shown in Table 3, average prices in the Baseline treatment are within 5\% of average prices in a perfectly competitive equilibrium. ${ }^{12}$ Consistent with the large literature on double auction experiments, efficiency in the Baseline treatment averages $98 \%$, suggesting that the environment is highly competitive and not susceptible to market power. ${ }^{13}$ As expected, Wald chi-squared tests in Table 5 confirm that there is no statistically significant difference in average prices between the Baseline and PC treatment in any of the three time intervals. Efficiency in the PC treatment also averages $98 \%$.

There are significant price effects when subjects could bank permits in the absence of price controls. Table 3 shows, and Tables 4 and 5 confirm that average permit prices under the Bank treatment in the first time interval are significantly higher than under any of the other treatments. Prices under the Bank treatment dropped significantly from Periods 1-2 to Periods 3$9(p=0.04)$, but still remained higher than the average prices for the Baseline and PC treatments in this second time interval (Table 5). In the final time interval, when there was a chance the

\footnotetext{
${ }^{12}$ For each of the three time intervals, the average competitive equilibrium price under the Baseline treatment depends upon the realization of stochastic demand shocks. The first two periods were known in advance to be Medium, with a competitive price of $\mathrm{E} \$ 230$. Given the sequences of random draws over periods 3-9, the average competitive price was $\mathrm{E} \$ 245$; in periods $10-13$, the average competitive price was $\mathrm{E} \$ 226$.

${ }^{13}$ Efficiency is defined as the ratio of the actual earnings to the maximum possible earnings.
} 
experiment would end after each round, average prices in the Bank treatment continued to fall ( $p$ $=0.00$ ), and were significantly below the average prices in the Baseline and PC treatments (Table 5).

The price effects under the Bank treatment are mitigated when banking and price controls are combined in the BankPC treatment. Figure 2 presents the mean prices (pooled over groups) for the Bank and BankPC treatments. Tests in Table 5 confirm that prices under the BankPC treatment in the first time interval are significantly lower than under the Bank treatment. BankPC prices are also lower in the middle interval, but not significantly so, and they are higher in the last interval, but again the difference is not significant. It is clear that, relative to the Bank treatment, BankPC prices start much lower and the path tends to be flatter.

The patterns we observe in the price paths of the Bank and BankPC treatments are entirely consistent with our theoretical predictions. Under the Bank treatment, prices are high in early periods as subjects accumulate permits to guard against potential bank shortages. Prices decline over time as the risk of a bank shortage is reduced and the continuation of the program becomes uncertain. Figure 3 shows that subjects tended to build up permit banks for the first six periods and then used most, but not all, of the permits over the remaining periods. The fact that there was a positive number of permits banked after period 10 suggests that some subjects continued to be concerned about bank shortages even when continuation of the experiment became uncertain.

Adding price controls to the banking environment results in lower initial prices because the price ceiling holds down early prices. Note in Figure 2 that average prices under the Bank treatment are above the price ceiling of the BankPC treatment in the first four periods. The left panel of Figure 4 shows the percent of trades under the Bank treatment that took place at prices 
equal to or higher than the price ceiling under the BankPC treatment (E\$265), as well as the percent of trades at prices at or below the BankPC price floor $(\mathrm{E} \$ 195)$. (The right-side panel of Figure 4 presents the percent of trades at the price ceiling and at the price floor under the BankPC treatment, which we will discuss shortly). Note that the majority of trades under the Bank treatment are at prices higher than the price ceiling of the BankPC treatment for the first five periods. It is clear that the price ceiling under the BankPC treatment suppresses prices in these initial periods. Also note in Figure 3 that subjects appear to build up smaller permit banks under the BankPC treatment than the Bank treatment; however, the difference is not statistically significant.

While the price ceiling under the BankPC treatment suppresses prices in early periods, which by itself would produce the flatter time series, it appears likely that the price floor also plays a role in smoothing the price series by holding up prices in later periods. Note in Figure 2 that the series of mean prices under the Bank treatment dips below the price floor of the Bank PC treatment in periods 11 and 12. Moreover, note in the left panel of Figure 4 that a high percentage of trades in later periods of the Bank treatment are at prices at or below the BankPC price floor (49\% in period $11,70 \%$ in period 12 , and about $34 \%$ in period 13 ).

\subsubsection{Between-period price volatility}

In analyzing price volatility we ignore the results from Periods 1-2 because, with only two periods in this interval, there is only one observation for each of the six groups. In Periods 3-9, it is clear that banking, price controls, and their combination all significantly reduce permit price volatility vis-à-vis the Baseline (Table 3 and Table 6). The difference in price volatility between the Bank and PC treatments is not statistically significant, but this may be due to the specific 
price controls used in the experiment. Tightening (loosening) the controls in the PC treatment could lead to significantly lower (higher) volatility than in the Bank treatment. More importantly, the combination of banking and price controls in the BankPC treatment leads to significantly less permit price volatility than either instrument alone (Table 6). ${ }^{14}$

Table 3 suggests an increase in volatility between Periods 3-9 and Periods 10-13 in all treatments, but this effect is statistically significant only in the Bank treatment $(p=0.00)$. As a consequence of the increase in volatility in the Bank treatment, there is not a significant difference in volatility between the Bank treatment and the Baseline in the last time interval and substantially more volatility under the Bank treatment in this interval than under the PC and BankPC treatments (Table 6).

\subsubsection{Within-period price dispersion}

The most dramatic feature of the within-period price dispersion results in Table 3 is that Baseline prices are significantly more disperse in the first two periods than in the Bank, PC, and BankPC treatments (significance tests are in Table 7). Thus, each policy reduces price dispersion relative to the Baseline in the early periods of the markets. However, price dispersion under the Baseline fell significantly from the first to the middle time interval $(p=0.00)$, and fell again in the last time interval $(p=0.05)$. Note from Table 7 that prices continued to be more disperse under the Baseline treatment than the other treatments in the middle time interval, but the differences are

\footnotetext{
14 The difference in price volatility between the Bank and BankPC treatment may not be as pronounced in a mature program with a zero chance that the program will end in the near future. In this setting we might expect more stable permit banking and more stable price series with both banking and banking combined with price controls, but the stabilizing effect may be greater on a program with banking alone.
} 
smaller. This trend continues into the last time interval, in which only the PC treatment has significantly lower price dispersion than the Baseline. Thus, while all the policies reduced price dispersion relative to the Baseline in the early periods, this effect diminished over time as price dispersion under the Baseline fell.

As for comparisons among the policy instruments, the tests in Table 7 reveal that there are no significant differences in price dispersion between PC and BankPC treatments. Price dispersion under BankPC is lower than under Bank, although only significantly lower in the final time interval. Thus, while combining banking and price controls more effectively reduces between-period price volatility than either instrument alone, combining the instruments does not have a clear advantage in terms of limiting within-period price dispersion. It is clear, however, that combining banking and price controls does not lead to greater price dispersion than either instrument alone.

\subsubsection{The use of the price controls}

We analyze the use of the price controls under the BankPC treatment differently than the PC treatment. Our theoretical model and results mentioned thus far suggest a temporal pattern in the use of the price controls in the BankPC treatment that is consistent with banking to smooth emissions through the random demand shocks. In contrast, under the PC treatment periods are independent because there is no banking, so fluctuations in the use of the price controls are determined by the random fluctuations in demand shocks.

Starting with the use of the price controls in the BankPC treatment, recall that we have argued that the price controls suppress prices in early periods and support prices in later periods. Consistent with this observation, the right panel of Figure 4 reveals that the price ceiling is 
triggered more frequently than the price floor in the first five periods of the sessions. In the first five rounds, $15 \%$ of trades were at the price ceiling and only $1 \%$ at the price floor. However, this difference is not significant $(p=0.17) .{ }^{15}$ In the last three rounds this pattern is reversed, with the price floor occurring significantly more often than the ceiling (30\% vs. $1 \%, p=0.03)$.

It is interesting to compare the percent of trades that trigger the price controls in the BankPC treatment with the percent of trades that meet or fall outside the price control bounds under the Bank treatment. There is a much higher percent of trades that meet or exceed the price ceiling in the first five periods of the Bank treatment (72\%) than trades that trigger the price ceiling in these periods under the BankPC treatment $(15 \%, p=0.00)$. In the last three rounds of the Bank treatment, $51 \%$ of trades are at or below the floor, which is higher than the $30 \%$ rate in the BankPC treatment $(p=0.09) .{ }^{16}$ One might expect these percentages to be roughly similar, but it appears that by truncating the range of possible trading prices, the price controls under the BankPC treatment tend to move prices away from their boundaries. ${ }^{17}$

As noted above, the use of the price controls under the PC treatment is determined by the fluctuations in demand shocks rather than dynamic subject strategies as in the BankPC treatment. Therefore, the left panel of Figure 5 presents the frequency with which the price controls are triggered in PC treatment by aggregate demand level. The right panel presents the frequencies in the Baseline treatment with which prices are at or above the PC price ceiling, at or below the PC

\footnotetext{
15 Statistical inferences in this subsection are based on an OLS regression model with the percent of trades as the dependent variable. The explanatory variables are dummy variables to capture combinations of the price controls (price ceiling and price floor), time intervals (periods 1-5 and 11-13), and the four treatments.

${ }^{16}$ There are not significant differences between the treatments in the percent of trades at or below the price floor in the first five periods and the percent of trades at or above the price ceiling in periods 11-13.

${ }^{17}$ This observation is consistent with the bidding patterns in double auction experimental markets with nonbinding price controls described in Isaac and Plott (1981), Smith and Williams (1981) and Smith and Williams (2008).
} 
price floor, and in the nonbinding range. Recall that theory suggests that prices should always be in the non-binding range in both treatments with the Medium aggregate permit demand. In Low demand periods the price floor would always bind in the PC treatment while prices would always be at or below the PC price floor in the Baseline treatment. In High demand periods, the price ceiling would always bind in the PC treatment while prices would always be at or exceed the PC price ceiling in the Baseline treatment.

One concern about emissions markets with price controls is that they will be used too often because they become focal prices. Moreover, if one control is activated more than the other, we may observe a situation in which new permits are created because too many trades occurred at the price ceiling, or too many permits are removed from the market as a result of too many trades at the price floor. Figure 5 shows that the price controls do not bind in $96 \%$ of trades in the Medium demand state under the PC treatment. This reveals that the price controls did not become focal points and were not activated more often than expected. In fact, Figure 5 shows that subjects did not use the price controls as often as predicted in either the Low or the High demand states. Only $46 \%$ of the trades occurred at the price ceiling in the High demand periods, far fewer than the competitive equilibrium prediction. Similarly, in the Low demand periods, only $65 \%$ of the trades occurred at the price floor. There appear to be two factors that explain this result. First, in the Baseline treatment, prices also fail to reach the PC price controls in the Low and High demand states as often as predicted. In the Baseline, only $54 \%$ of trades are at or above the ceiling in High demand periods and $84 \%$ of trades are at or below the floor in Low demand periods. The difference in the percent of trades at or above the price ceiling in the High demand state between the two treatments is not statistically significant ( $54 \%$ vs. $46 \%, p=0.28$ ), but the percent of trades at or below the price floor in the Low demand state is significantly 
higher in the Baseline treatment $(84 \%$ vs. $65 \%, p=0.07) .{ }^{18}$ Thus, part of the reason the price controls are not activated as often as predicted in the PC treatment is that prices under the Baseline do not reach the levels of the PC controls as often as predicted. The other reason, as already noted, is likely to be that the presence of the price controls in the PC treatment truncates the range of possible bids and asks, moving prices away from their boundaries.

\subsection{Emissions}

The analysis now focuses on aggregate emissions for each group in each period and the betweenperiod variation in this variable (emissions volatility). Table 8 presents unconditional means of aggregate emissions and emissions volatility, respectively, by treatment and time interval. We do not include Baseline emission levels, because these are constant at 40 units per period. Table 9 presents the results of linear random effects models with the same structure as the price regressions in Table 4, except that the dependent variables are aggregate emissions and emissions volatility, the Baseline treatment values are not included, and the omitted treatment is BankPC. Tables 10 and 11 provide hypothesis tests of treatment differences.

\subsubsection{Aggregate emissions}

Table 8 may suggest that there are some differences in aggregate emissions over time in both the PC and BankPC treatments. However, the differences across time intervals for a given treatment

\footnotetext{
18 These statements about statistical significance are based on the results of random effects logit models using data from Periods 1-13. For one model the dependent variable equals 1 if the trade occurred at the price ceiling (or above in the Baseline case). For the other model the dependent variable equals 1 if the trade occurred at the price floor (or below in the Baseline case).
} 
are not statistically significant, except for a significant difference $(p=0.07)$ between average emissions in Period 1-2 and Periods 10-13 under the BankPC treatment. In addition, the results in Table 9 show that there are no significant differences between the two price control treatments in any time interval. It is interesting that, with the exception of BankPC in the last time interval, aggregate emissions for each price control treatment in each time interval averaged slightly less than the 40 units per period permit allocation. This is important because it suggests that the inclusion of symmetric price controls need not have significant effects on aggregate emissions over the life of a program.

However, there are significant time effects in the Bank treatment. Emissions are significantly lower in Periods 1-2 than Periods 3-9 $(p=0.02)$, and significantly higher in Periods 10-13 than Periods 3-9 $(p=0.00)$. This is consistent with individuals building up their permit banks early and then drawing down these banks in later periods (recall Figure 2).

\subsubsection{Emissions volatility}

Ignoring the Period 1-2 results because of the low number of observations, Table 11 reveals that each of the policies in the PC, Bank, and BankPC treatments lead to significant emissions volatility. The Baseline, of course, has no volatility because emissions are constant in every period. As expected, relative to the Baseline, each of the policies effectively reduces price volatility in exchange for a significant increase in emissions volatility.

The tradeoff between price and emissions volatility is also apparent in comparisons among the treatments. Comparing price and emissions volatility results in Tables 6 and 11 reveals that a policy that produces a significant reduction in price volatility does not simultaneously produce a reduction in emissions volatility. For example, in Periods 3-9, price 
volatility is significantly lower under the BankPC treatments than under the Bank and PC treatments. At the same time, emissions volatility is significantly higher under the BankPC treatment than under the PC treatment, and there is not a significant difference in emissions volatility between the Bank and BankPC treatments. Symmetrically, a policy that produces significantly lower emissions volatility does not produce significantly lower price volatility. Again in Periods 3-9, note from Table 11 that emissions volatility is lower under the PC treatment than under the Bank and BankPC treatments. In Table 6 we see that the PC treatment involves significantly higher price volatility than the BankPC treatment and about the same degree of price volatility as the Bank treatment.

\section{Conclusion}

We have conducted laboratory emissions trading experiments to investigate the performance of banking and price controls in limiting permit price risk produced by uncertain abatement costs. Our results yield important lessons for designing emissions markets under abatement cost uncertainty. While it is clear that both banking and price controls can limit permit price volatility and dispersion, combining the instruments produces important benefits over using either of them alone. Permit price volatility is significantly lower under a combined policy than under banking alone or price controls alone, and price dispersion is never significantly higher under the combined policy than the separate polices. Thus, combining banking and price controls can produce more stable prices across time periods without adding noise to within-period price distributions. Moreover, banking alone produces high permit prices in earlier periods that fall over time, but the combined policy produces lower initial prices and a flatter time series. This is mainly due to the price ceiling suppressing permit prices in early periods, but the price floor 
likely plays a role because it holds up price in later periods One potential downside is that each measure to contain permit price risk produces higher emissions volatility. Thus, care must be taken when using any of the policies considered in this paper to control a flow pollutant that produces strictly convex damages. 
Figure 1. Permit demand shocks and price controls

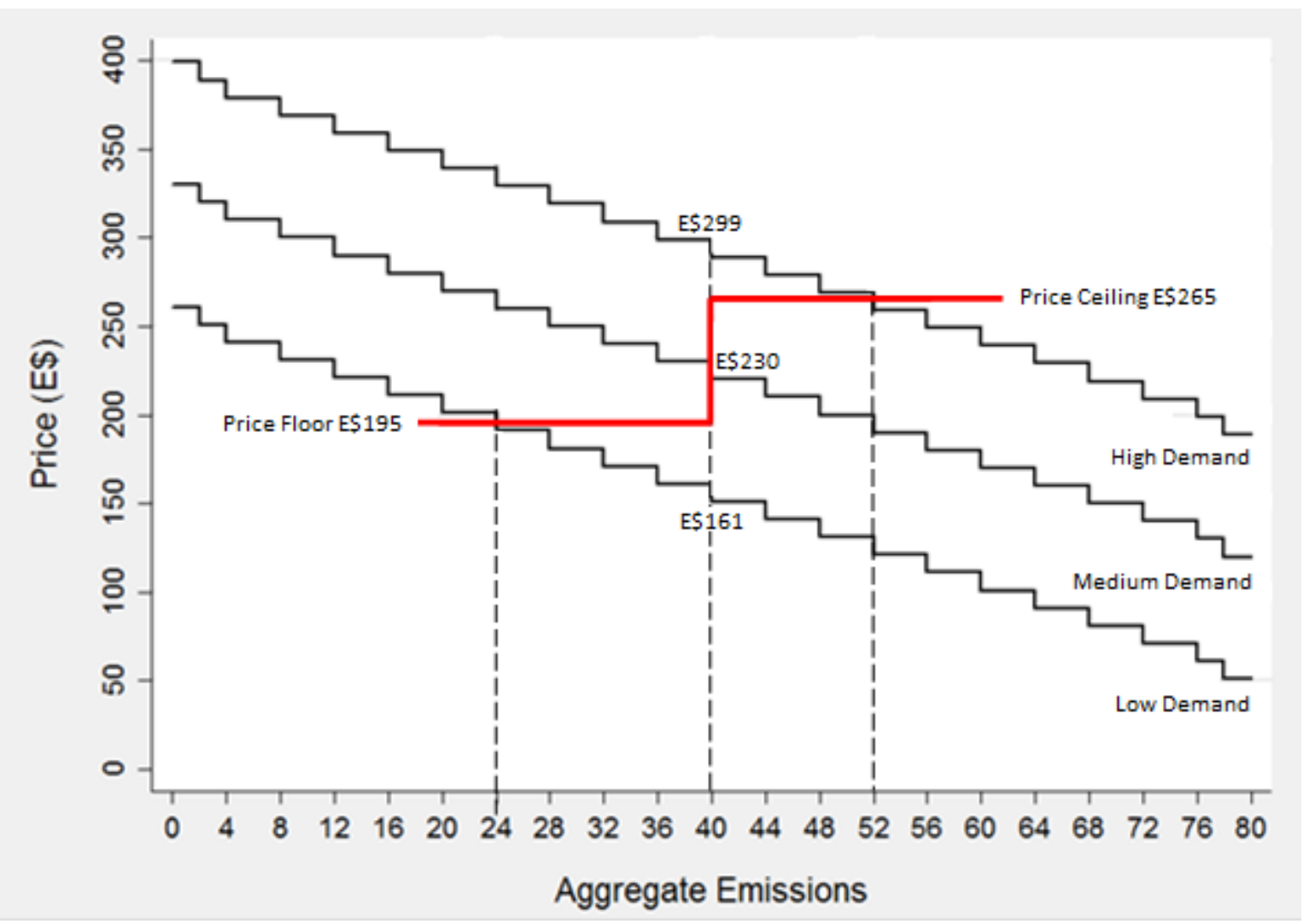


Figure 2. Mean Permit Prices for Banking Treatments

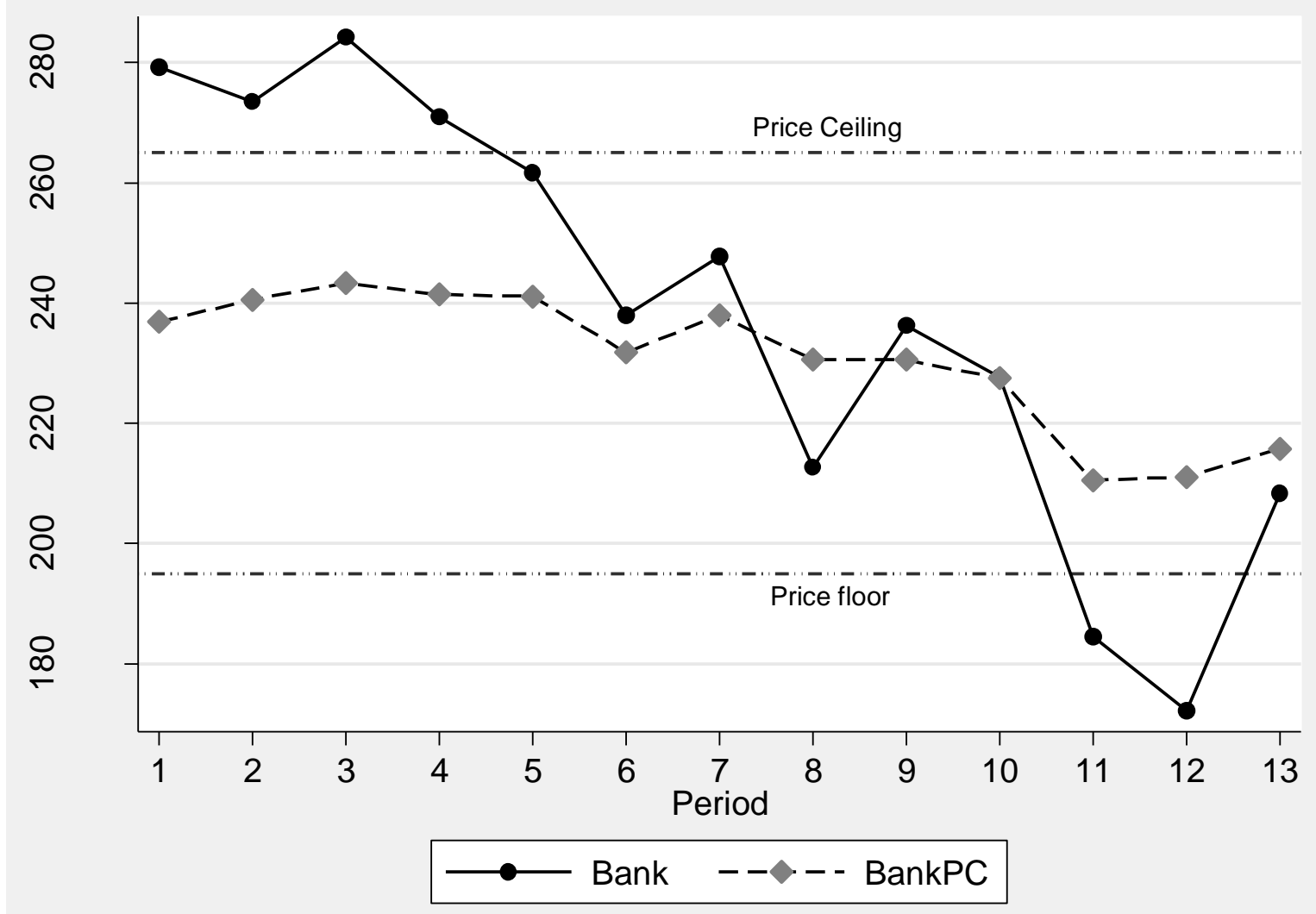


Figure 3. Mean Aggregate Permits Banked

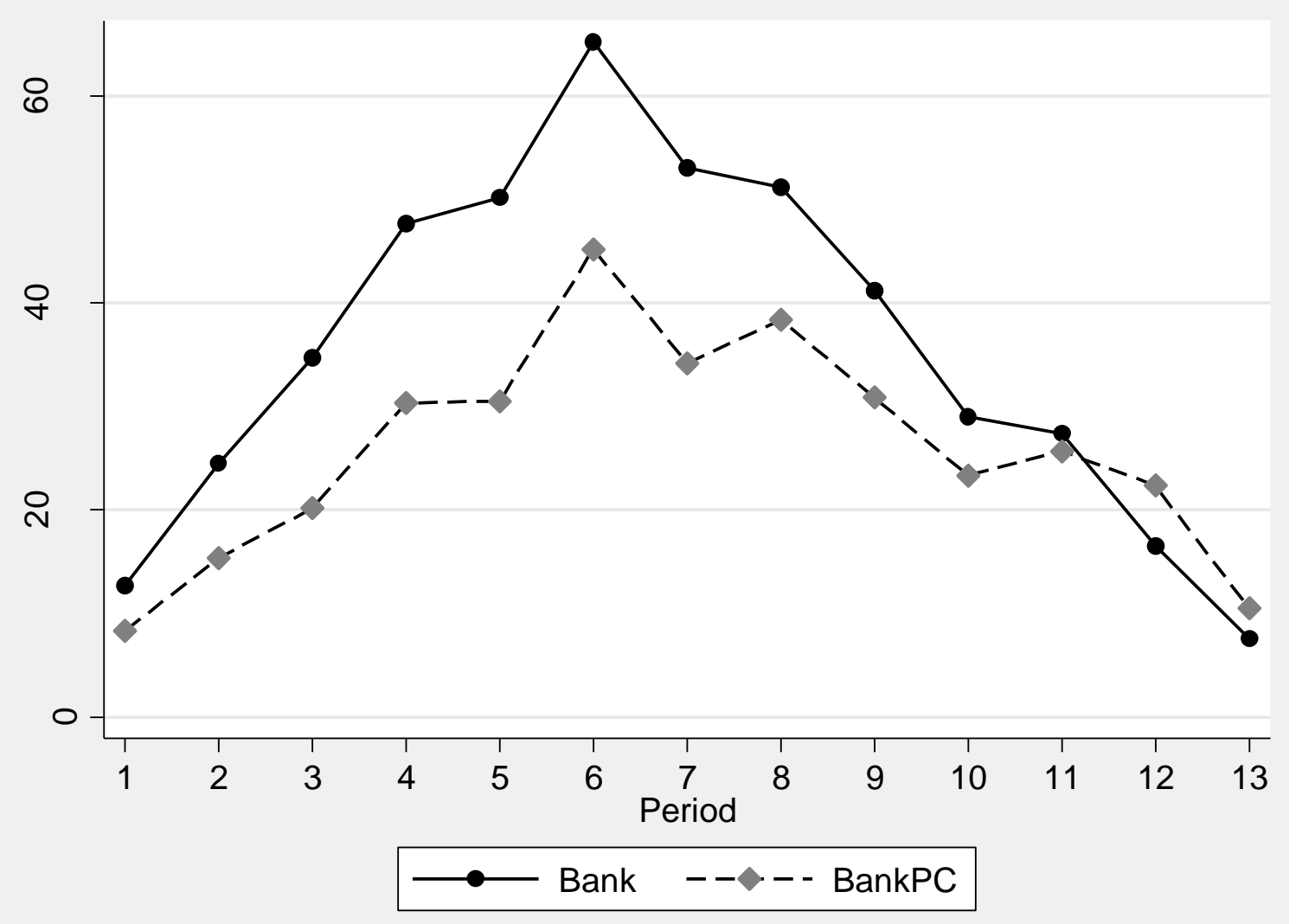


Figure 4. Percent of Trades at the Price Controls over Time

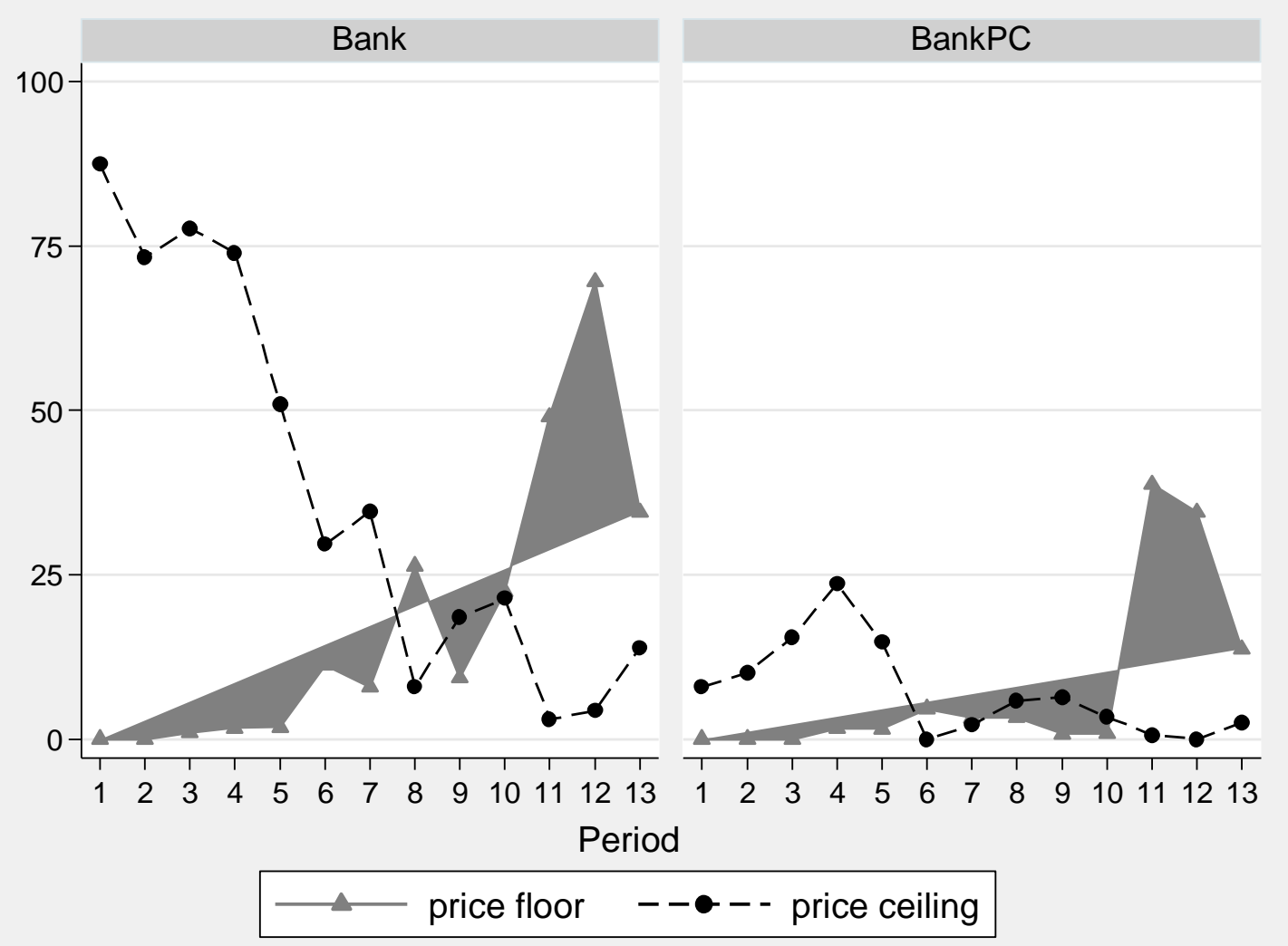

Note: The price controls were not in effect for the Bank treatment. For the purposes of this figure, the price floor tracks trades at or below 195. Similarly, the price ceiling tracks trades at or above 265 . 
Figure 5. Distribution of Prices by Treatment, Periods 1-13

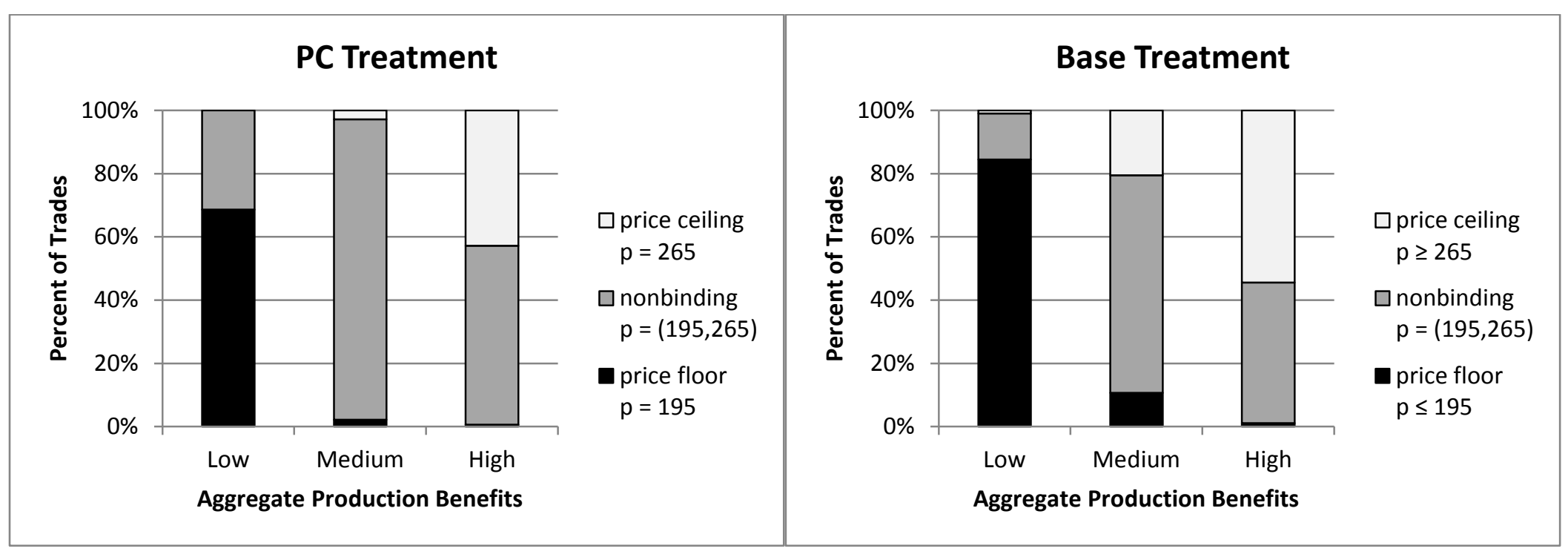


Table 1. Marginal Production Earnings/Individual Permit Demand Schedules

\begin{tabular}{cccccccccccccc}
\hline \multirow{2}{*}{$\begin{array}{c}\text { Units } \\
\text { Produced }\end{array}$} & \multicolumn{10}{c}{ A } & A & \multicolumn{10}{c}{ B } & \multicolumn{1}{c}{ Subject Type } \\
\hline & L & M & H & L & M & H & L & M & H & L & M & H \\
\hline 1 & 261 & 330 & 399 & 251 & 320 & 389 & 241 & 310 & 379 & 231 & 300 & 369 \\
2 & 241 & 310 & 379 & 231 & 300 & 369 & 221 & 290 & 359 & 211 & 280 & 349 \\
3 & 221 & 290 & 359 & 211 & 280 & 349 & 201 & 270 & 339 & 191 & 260 & 329 \\
4 & 201 & 270 & 339 & 191 & 260 & 329 & 181 & 250 & 319 & 171 & 240 & 309 \\
5 & 181 & 250 & 319 & 171 & 240 & 309 & 161 & 230 & 299 & 151 & 220 & 289 \\
6 & 161 & 230 & 299 & 151 & 220 & 289 & 141 & 210 & 279 & 131 & 200 & 269 \\
7 & 141 & 210 & 279 & 131 & 200 & 269 & 121 & 190 & 259 & 111 & 180 & 249 \\
8 & 121 & 190 & 259 & 111 & 180 & 249 & 101 & 170 & 239 & 91 & 160 & 229 \\
9 & 101 & 170 & 239 & 91 & 160 & 229 & 81 & 150 & 219 & 71 & 140 & 209 \\
10 & 81 & 150 & 219 & 71 & 140 & 209 & 61 & 130 & 199 & 51 & 120 & 189 \\
\hline
\end{tabular}

In each 8-person group, there were two subjects of each type. The sub-headings L, M, H refer to Low, Medium and High demand. 
Table 2. Random Sequences of Demand Shocks

\begin{tabular}{ccccc}
\hline Period & Sequence 1 & Sequence 2 & Sequence 3 & Sequence 4 \\
\hline $\mathbf{1}$ & $\mathrm{M}$ & $\mathrm{M}$ & $\mathrm{M}$ & $\mathrm{M}$ \\
$\mathbf{2}$ & $\mathrm{M}$ & $\mathrm{M}$ & $\mathrm{M}$ & $\mathrm{M}$ \\
$\mathbf{3}$ & $\mathrm{H}$ & $\mathrm{L}$ & $\mathrm{H}$ & $\mathrm{M}$ \\
$\mathbf{4}$ & $\mathrm{M}$ & $\mathrm{L}$ & $\mathrm{H}$ & $\mathrm{M}$ \\
$\mathbf{5}$ & $\mathrm{H}$ & $\mathrm{M}$ & $\mathrm{M}$ & $\mathrm{M}$ \\
$\mathbf{6}$ & $\mathrm{M}$ & $\mathrm{L}$ & $\mathrm{L}$ & $\mathrm{M}$ \\
$\mathbf{7}$ & $\mathrm{M}$ & $\mathrm{H}$ & $\mathrm{H}$ & $\mathrm{H}$ \\
$\mathbf{8}$ & $\mathrm{L}$ & $\mathrm{M}$ & $\mathrm{H}$ & $\mathrm{H}$ \\
$\mathbf{9}$ & $\mathrm{M}$ & $\mathrm{H}$ & $\mathrm{H}$ & $\mathrm{M}$ \\
$\mathbf{1 0}$ & $\mathrm{M}$ & $\mathrm{H}$ & $\mathrm{M}$ & $\mathrm{H}$ \\
$\mathbf{1 1}$ & $\mathrm{L}$ & $\mathrm{L}$ & $\mathrm{M}$ & $\mathrm{M}$ \\
$\mathbf{1 2}$ & $\mathrm{H}$ & $\mathrm{L}$ & $\mathrm{L}$ & $\mathrm{M}$ \\
$\mathbf{1 3}$ & $\mathrm{M}$ & $\mathrm{H}$ & $\mathrm{M}$ & $\mathrm{L}$ \\
$\mathbf{1 4}$ & & $\mathrm{L}$ & $\mathrm{M}$ & $\mathrm{M}$ \\
$\mathbf{1 5}$ & & $\mathrm{L}$ & $\mathrm{M}$ & $\mathrm{H}$ \\
$\mathbf{1 6}$ & & $\mathrm{H}$ & $\mathrm{M}$ & \\
$\mathbf{1 7}$ & & $\mathrm{L}$ & & \\
$\mathbf{1 8}$ & & $\mathrm{M}$ & & \\
$\mathbf{1 9}$ & & $\mathrm{L}$ & & \\
$\mathbf{2 0}$ & & $\mathrm{L}$ & & \\
\hline
\end{tabular}

L=Low, M=Medium, H=High permit demand. 
Table 3. Mean Permit Price, Volatility and Dispersion by Treatment and Period Interval ${ }^{\mathrm{a}}$

\begin{tabular}{|c|c|c|c|c|c|c|c|c|c|}
\hline \multirow[b]{2}{*}{ Treatment } & \multicolumn{3}{|c|}{ Permit Price } & \multicolumn{3}{|c|}{$\begin{array}{l}\text { Between Period } \\
\text { Price Volatility } \\
\end{array}$} & \multicolumn{3}{|c|}{$\begin{array}{c}\text { Within Period } \\
\text { Price Dispersion }\end{array}$} \\
\hline & $\begin{array}{r}\text { Periods } \\
1-2 \\
\end{array}$ & $\begin{array}{r}\text { Periods } \\
\text { 3-9 } \\
\end{array}$ & $\begin{array}{r}\text { Periods } \\
10-13 \\
\end{array}$ & $\begin{array}{r}\text { Periods } \\
1-2 \\
\end{array}$ & $\begin{array}{r}\text { Periods } \\
\text { 3-9 } \\
\end{array}$ & $\begin{array}{r}\text { Periods } \\
10-13 \\
\end{array}$ & $\begin{array}{r}\text { Periods } \\
1-2 \\
\end{array}$ & $\begin{array}{r}\text { Periods } \\
\text { 3-9 } \\
\end{array}$ & $\begin{array}{r}\text { Periods } \\
10-13 \\
\end{array}$ \\
\hline Baseline & $\begin{array}{r}239.1 \\
(33.12)\end{array}$ & $\begin{array}{r}232.6 \\
(47.03)\end{array}$ & $\begin{array}{r}220.9 \\
(48.75)\end{array}$ & $\begin{array}{r}28.5 \\
(12.75)\end{array}$ & $\begin{array}{r}42.6 \\
(30.85)\end{array}$ & $\begin{array}{r}50.8 \\
(43.21)\end{array}$ & $\begin{array}{r}41.8 \\
(32.35)\end{array}$ & $\begin{array}{r}19.0 \\
(10.26)\end{array}$ & $\begin{array}{r}14.5 \\
(7.60)\end{array}$ \\
\hline PC & $\begin{array}{r}227.4 \\
(12.84)\end{array}$ & $\begin{array}{r}232.6 \\
(24.41)\end{array}$ & $\begin{array}{r}223.3 \\
(24.57)\end{array}$ & $\begin{array}{r}8.8 \\
(4.00)\end{array}$ & $\begin{array}{r}19.1 \\
(15.49)\end{array}$ & $\begin{array}{r}27.4 \\
(20.33)\end{array}$ & $\begin{array}{r}10.4 \\
(3.35)\end{array}$ & $\begin{array}{r}5.4 \\
(2.90)\end{array}$ & $\begin{array}{r}4.6 \\
(3.68)\end{array}$ \\
\hline Bank & $\begin{array}{r}276.2 \\
(20.98)\end{array}$ & $\begin{array}{r}250.4 \\
(37.86)\end{array}$ & $\begin{array}{r}197.5 \\
(43.90)\end{array}$ & $\begin{array}{r}13.2 \\
(7.01)\end{array}$ & $\begin{array}{r}22.1 \\
(19.21)\end{array}$ & $\begin{array}{r}38.9 \\
(29.51)\end{array}$ & $\begin{array}{r}9.8 \\
(4.83)\end{array}$ & $\begin{array}{r}14.3 \\
(6.97)\end{array}$ & $\begin{array}{r}16.3 \\
(9.38)\end{array}$ \\
\hline BankPC & $\begin{array}{r}238.7 \\
(12.63) \\
\end{array}$ & $\begin{array}{r}236.6 \\
(16.59) \\
\end{array}$ & $\begin{array}{r}215.8 \\
(14.87) \\
\end{array}$ & $\begin{array}{r}6.0 \\
(4.87) \\
\end{array}$ & $\begin{array}{r}9.0 \\
(7.80) \\
\end{array}$ & $\begin{array}{r}15.5 \\
(9.22) \\
\end{array}$ & $\begin{array}{r}10.5 \\
(3.34) \\
\end{array}$ & $\begin{array}{r}9.3 \\
(6.93) \\
\end{array}$ & $\begin{array}{r}8.9 \\
(4.95) \\
\end{array}$ \\
\hline
\end{tabular}

${ }^{\mathrm{a}}$ Standard deviations in parentheses.

${ }^{\mathrm{b}}$ Price volatility is defined as the mean absolute difference in the mean price for a given group between periods $t$ and $t-1$.

${ }^{c}$ Price dispersion is defined as the absolute difference between each trading price in a period and that period's mean price. 
Table 4. Linear Random Effects Models of Permit Prices, Volatility, and Dispersion

\begin{tabular}{|c|c|c|c|c|c|c|}
\hline \multirow[b]{2}{*}{ Variable } & \multicolumn{2}{|c|}{ Permit price } & \multicolumn{2}{|c|}{ Price volatility } & \multicolumn{2}{|c|}{ Price dispersion } \\
\hline & Coefficient & $\begin{array}{l}\text { Std. } \\
\text { Error }\end{array}$ & Coefficient & $\begin{array}{l}\text { Std. } \\
\text { Error }\end{array}$ & Coefficient & $\begin{array}{l}\text { Std. } \\
\text { Error }\end{array}$ \\
\hline Constant & $241.74 * * *$ & 8.67 & $29.67 * * *$ & 5.45 & $15.13 * * *$ & 3.31 \\
\hline $\mathrm{PC}$ & 1.91 & 8.85 & $-23.10 * * *$ & 5.45 & $-12.80 * * *$ & 3.23 \\
\hline Bank & $20.32 * *$ & 8.85 & $-22.78 * * *$ & 5.45 & -4.79 & 3.23 \\
\hline BankPC & 7.44 & 8.85 & $-33.68 * * *$ & 5.45 & $-9.82 * * *$ & 3.23 \\
\hline \multicolumn{7}{|l|}{ Periods $1-2 \times$} \\
\hline Baseline & 9.67 & 10.10 & -13.78 & 9.58 & $20.64 * * *$ & 2.53 \\
\hline $\mathrm{PC}$ & -7.34 & 10.10 & -11.50 & 9.58 & $4.94 * *$ & 2.53 \\
\hline Bank & $20.21 * *$ & 10.10 & -7.84 & 9.58 & -3.56 & 2.53 \\
\hline BankPC & 0.94 & 10.10 & -2.97 & 9.58 & 1.31 & 2.53 \\
\hline \multicolumn{7}{|l|}{ Periods $10-13 \times$} \\
\hline Baseline & -9.47 & 7.89 & 5.74 & 5.62 & $-3.88 * *$ & 1.97 \\
\hline $\mathrm{PC}$ & -6.14 & 7.89 & 6.67 & 5.62 & -0.72 & 1.97 \\
\hline Bank & $-49.50 * * *$ & 7.89 & $19.18 * * *$ & 5.62 & 1.82 & 1.97 \\
\hline BankPC & $-19.73 * *$ & 7.89 & 6.66 & 5.62 & 0.22 & 1.97 \\
\hline Sequence 1 & -4.88 & 8.04 & $17.24 * * *$ & 4.77 & 4.51 & 3.21 \\
\hline Sequence 2 & $-23.83 * * *$ & 8.04 & $17.97 * * *$ & 4.77 & 4.67 & 3.21 \\
\hline Sequence 3 & -10.96 & 9.29 & $12.15 * *$ & 5.50 & 2.04 & 3.71 \\
\hline \# Observations & 312 & & 288 & & 312 & \\
\hline \# Groups & 24 & & 24 & & 24 & \\
\hline
\end{tabular}


Table 5. Treatment Differences in Mean Prices

\begin{tabular}{lccc}
\hline Treatment difference & Periods 1-2 & Periods 3-9 & Periods 10-13 \\
\hline Baseline - PC & 15.10 & -1.91 & -5.24 \\
Baseline - Bank & $-30.86^{* *}$ & $-20.32^{* *}$ & $19.71^{*}$ \\
Baseline - BankPC & 1.29 & -7.44 & 2.82 \\
PC - Bank & $-45.96^{* * *}$ & $-18.41^{* *}$ & $24.95^{* *}$ \\
PC - BankPC & -13.81 & -5.53 & 8.06 \\
Bank - BankPC & $32.15^{* *}$ & 12.88 & -16.89 \\
\hline
\end{tabular}

Values in the table are the difference in estimated average prices between treatments using the random effects model in Table 4 . Wald chi-squared tests were used to test the null hypothesis of no difference in average prices. $* * * p<0.01$, ** $p<0.05, * p<0.1$.

Table 6. Treatment Differences in Between-Period Price Volatility

\begin{tabular}{lccc}
\hline Treatment difference & Periods 1-2 & Periods 3-9 & Periods 10-13 \\
\hline Baseline - PC & 20.82 & $23.10^{* * *}$ & $22.17^{* * *}$ \\
Baseline - Bank & 16.84 & $22.78^{* * * *}$ & 9.35 \\
Baseline - BankPC & $22.87^{*}$ & $33.68^{* * *}$ & $32.76^{* * *}$ \\
PC - Bank & -3.97 & -0.31 & $-12.82^{* *}$ \\
PC - BankPC & 2.05 & $10.58^{* * *}$ & 10.59 \\
Bank - BankPC & 6.03 & $10.89 * *$ & $23.41^{* * *}$ \\
\hline
\end{tabular}

Values in the table are the difference in estimated price volatility between treatments. Wald chisquared tests were used to test the null hypothesis of no difference in price volatility.

$* * * p<0.01, * * p<0.05, * p<0.1$. 
Table 7. Treatment Differences in Within-Period Price Dispersion

\begin{tabular}{lccc}
\hline Treatment difference & Periods 1-2 & Periods 3-9 & Periods 10-13 \\
\hline Baseline - PC & $28.50^{* * *}$ & $12.80^{* * *}$ & $9.64^{* * *}$ \\
Baseline - Bank & $28.98^{* * *}$ & 4.79 & -0.92 \\
Baseline - BankPC & $29.15^{* * *}$ & $9.82^{* * *}$ & 5.72 \\
PC - Bank & 0.48 & $-8.02^{* * *}$ & $-10.56^{* * *}$ \\
PC - BankPC & 0.65 & -2.98 & -3.92 \\
Bank - BankPC & 0.17 & 5.04 & $6.64^{* *}$ \\
\hline
\end{tabular}

Values in the table are the difference in estimated price dispersion between treatments.

Wald chi-squared tests were used to test the null hypothesis of no difference in price dispersion. $* * * p<0.01, * * p<0.05, * p<0.1$.

Table 8. Mean Aggregate Emissions and Volatility by Treatment and Period Interval ${ }^{\mathrm{a}, \mathrm{b}}$

\begin{tabular}{|c|c|c|c|c|c|c|}
\hline \multirow[b]{2}{*}{ Treatment } & \multicolumn{3}{|c|}{ Aggregate Emissions } & \multicolumn{3}{|c|}{$\begin{array}{c}\text { Between Period } \\
\text { Aggregate Emissions Volatility }^{\mathrm{c}}\end{array}$} \\
\hline & $\begin{array}{r}\text { Periods } \\
1-2\end{array}$ & $\begin{array}{r}\text { Periods } \\
\text { 3-9 }\end{array}$ & $\begin{array}{r}\text { Periods } \\
10-13\end{array}$ & $\begin{array}{r}\text { Periods } \\
1-2\end{array}$ & $\begin{array}{r}\text { Periods } \\
\text { 3-9 }\end{array}$ & $\begin{array}{r}\text { Periods } \\
10-13\end{array}$ \\
\hline $\mathrm{PC}$ & $\begin{array}{l}39.8 \\
(0.7)\end{array}$ & $\begin{array}{r}39.3 \\
(8.4)\end{array}$ & $\begin{array}{l}36.1 \\
(9.6)\end{array}$ & $\begin{array}{r}1.0 \\
(0.9)\end{array}$ & $\begin{array}{r}8.1 \\
(7.0)\end{array}$ & $\begin{array}{l}10.7 \\
(8.5)\end{array}$ \\
\hline Bank & $\begin{array}{r}27.8 \\
(5.5)\end{array}$ & $\begin{array}{r}37.7 \\
(17.5)\end{array}$ & $\begin{array}{r}48.0 \\
(11.9)\end{array}$ & $\begin{array}{r}3.3 \\
(1.4)\end{array}$ & $\begin{array}{r}15.2 \\
(12.0)\end{array}$ & $\begin{array}{l}13.0 \\
(9.5)\end{array}$ \\
\hline BankPC & $\begin{array}{l}32.8 \\
(3.3) \\
\end{array}$ & $\begin{array}{r}38.5 \\
(15.4) \\
\end{array}$ & $\begin{array}{r}41.0 \\
(14.3) \\
\end{array}$ & $\begin{array}{r}2.7 \\
(1.5)\end{array}$ & $\begin{array}{r}17.3 \\
(11.2) \\
\end{array}$ & $\begin{array}{r}16.7 \\
(11.6) \\
\end{array}$ \\
\hline
\end{tabular}

${ }^{\mathrm{a}}$ Standard deviations in parentheses.

${ }^{\mathrm{b}}$ Baseline omitted because emissions were constant at 40 .

${ }^{\mathrm{c}}$ Emissions volatility is defined as the mean absolute difference in the mean aggregate emissions for a given group between periods $t$ and $t-1$. 
Table 9: Linear Random Effects Models of Emissions and Emissions Volatility

\begin{tabular}{|c|c|c|c|c|}
\hline \multirow[b]{2}{*}{ Variable } & \multicolumn{2}{|c|}{ Aggregate emissions } & \multicolumn{2}{|c|}{ Emissions volatility } \\
\hline & Coefficient & $\begin{array}{c}\text { Std. } \\
\text { Error }\end{array}$ & Coefficient & $\begin{array}{c}\text { Std. } \\
\text { Error }\end{array}$ \\
\hline Constant & $38.42 * * *$ & 2.68 & $13.41 * * *$ & 2.11 \\
\hline PC & 0.79 & 2.75 & $-9.17 * * *$ & 2.12 \\
\hline Bank & -0.88 & 2.75 & -2.07 & 2.12 \\
\hline \multicolumn{5}{|l|}{ Periods 1-2 } \\
\hline PC & 0.50 & 4.13 & $-7.14^{*}$ & 4.24 \\
\hline Bank & $-9.83 * *$ & 4.13 & $-11.90 * * *$ & 4.24 \\
\hline BankPC & -5.71 & 4.13 & $-14.64 * * *$ & 4.24 \\
\hline \multicolumn{5}{|l|}{ Periods $10-13$} \\
\hline $\mathrm{PC}$ & -3.25 & 3.23 & 2.52 & 2.16 \\
\hline Bank & $10.33 * * *$ & 3.23 & -2.20 & 2.16 \\
\hline BankPC & 2.45 & 3.23 & -0.64 & 2.16 \\
\hline Sequence 1 & 0.87 & 2.48 & $4.92 * *$ & 1.99 \\
\hline Sequence 2 & -1.01 & 2.48 & $5.01 * *$ & 1.99 \\
\hline Sequence 3 & 1.08 & 2.48 & 3.53 & 2.29 \\
\hline \# Observations & 234 & & 216 & \\
\hline \# Groups & 18 & & 18 & \\
\hline
\end{tabular}


Table 10. Treatment Differences in Aggregate Emissions

\begin{tabular}{lccc}
\hline Treatment differences & Periods 1-2 & Period 3-9 & Periods 10-13 \\
\hline Baseline - PC & 0.17 & 0.55 & 3.92 \\
Baseline - Bank & 12.17 *** & 2.21 & $-8.00 * * *$ \\
Baseline - BankPC & 7.17 & 1.33 & -1.00 \\
PC - Bank & 12.00 *** & 1.67 & $-11.92 * * *$ \\
PC - BankPC & 7.00 & 0.79 & -4.92 \\
Bank - BankPC & -5.00 & -0.88 & 7.00 \\
\hline
\end{tabular}

Values in the table are the difference in estimated aggregate emissions between treatments. Wald chi-squared tests were used to test the null hypothesis of no difference in aggregate emissions. $* * * p<0.01, * * p<0.05, * p<0.1$.

Table 11. Treatment Differences in Emissions Volatility

\begin{tabular}{lccc}
\hline Treatment differences & Periods 1-2 & Period 3-9 & Periods 10-13 \\
\hline Baseline - PC & -1.00 & $-7.95 * * *$ & $-10.67 * * *$ \\
Baseline - Bank & -3.33 & $-15.05 * * *$ & $-13.04 * * *$ \\
Baseline - BankPC & -2.67 & $-17.22 * * *$ & $-16.67 * * *$ \\
PC - Bank & -2.33 & $-7.10 * * *$ & -2.38 \\
PC - BankPC & -1.67 & $-9.17 * * *$ & $-6.00 * * *$ \\
Bank - BankPC & 0.67 & -2.07 & -3.62 \\
\hline
\end{tabular}

Values in the table are the difference in estimated emissions volatility between treatments. Wald chi-squared tests were used to test the null hypothesis of no difference in emissions volatility. $* * * p<0.01, * * p<0.05, * p<0.1$. 


\section{Appendix: A model of permit banking with price controls}

The stochastic dynamic programming problem is to choose $\left(Q_{0}, Q_{1}, \ldots\right),\left(y_{0}^{c}, y_{1}^{c}, \ldots\right)$ and $\left(y_{0}^{f}, y_{1}^{f}, \ldots\right)$ to solve:

$$
\begin{aligned}
& \max E_{0}\left[\sum_{t=0}^{\infty} \alpha_{t}(1+\mu)^{-t}\left(B\left(Q_{t}, u_{t}\right)-p_{t}^{c} y_{t}^{c}+p_{t}^{f} y_{t}^{f}\right)\right] \\
& \text { s.t. } S_{t+1}=S_{t}+L_{t}-Q_{t}+y_{t}^{c}-y_{t}^{f} \geq 0 \\
& \qquad y_{t}^{c} \geq 0, y_{t}^{f} \geq 0 .
\end{aligned}
$$

Our approach to analyzing this problem is the same as Schennach's (2000), but with the addition of the price controls and the random terminal date. Define the value function

$$
V_{t}\left(S_{t}\right)=\max _{Q_{t}, y_{t}^{c}, y_{t}^{f}} F_{t}\left(S_{t}, Q_{t}, y_{t}^{c}, y_{t}^{f}\right)
$$

where

$$
\begin{gathered}
F_{t}\left(S_{t}, Q_{t}, y_{t}^{c}, y_{t}^{f}\right)=B\left(Q_{t}, u_{t}\right)-p_{t}^{c} y_{t}^{c}+p_{t}^{f} y_{t}^{f}+\alpha_{t+1}(1+\mu)^{-1} E_{t}\left(V_{t+1}\left(S_{t+1}\right)\right) \\
+\lambda_{t}\left(S_{t}+L_{t}-Q_{t}+y_{t}^{c}-y_{t}^{f}\right)
\end{gathered}
$$

We do not multiply the first three terms in (A3) by $\alpha_{t}$ because we are considering decisions in $t$ so it must be the case that $\alpha_{t}=1$. The first order conditions for $Q_{t}, y_{t}^{c}, y_{t}^{f}$ and $\lambda_{t}$ can be written, respectively, as:

$$
\begin{aligned}
& B_{Q}\left(Q_{t}, u_{t}\right)-\lambda_{t}=\alpha_{t+1}(1+\mu)^{-1} E_{t}\left(\frac{\partial V_{t+1}\left(S_{t+1}\right)}{\partial S_{t+1}}\right) ; \\
& p_{t}^{c}-\lambda_{t} \geq \alpha_{t+1}(1+\mu)^{-1} E_{t}\left(\frac{\partial V_{t+1}\left(S_{t+1}\right)}{\partial S_{t+1}}\right), \text { if }>, y_{t}^{c}=0 ; \\
& p_{t}^{f}-\lambda_{t} \leq \alpha_{t+1}(1+\mu)^{-1} E_{t}\left(\frac{\partial V_{t+1}\left(S_{t+1}\right)}{\partial S_{t+1}}\right), \text { if }<, y_{t}^{f}=0 ;
\end{aligned}
$$




$$
\lambda_{t} \geq 0, S_{t}+L_{t}-Q_{t}+y_{t}^{c}-y_{t}^{f} \geq 0 \text {, and } \lambda_{t}\left(S_{t}+L_{t}-Q_{t}+y_{t}^{c}-y_{t}^{f}\right)=0 \text {. }
$$

(A4) through (A6) reveal that $p_{t}^{f} \leq p_{t} \leq p_{t}^{c}$, so the permit price in a period is bounded by the price controls. Moreover, note that $\alpha_{t+1}(1+\mu)^{-1} E_{t}\left(\partial V_{t+1}\left(S_{t+1}\right) / \partial S_{t+1}\right)$ is the expected present value of increasing the bank for $t+1$, discounted by the likelihood the program continues into that period. Suppose that (A5) holds with equality and $S_{t+1}>0$ so that $\lambda_{t}=0$. The resulting first order condition implies that when the price ceiling binds, firms will purchase additional permits from the government up the point where the expected discounted value (including the $\alpha$ discount) of adding to the permit bank is equal to the price ceiling. A similar interpretation for behavior at the price floor can be gleaned from (A6). (A7) implies that the multiplier attached to the no-borrowing constraint in a period is non-negative, the stock of permits at the end of the period is non-negative, and the product of the two is equal to zero. Therefore, the multiplier is only positive when the aggregate bank of permits is empty at the end of a period-it is equal to zero when the bank is not empty.

Let us now derive equation (3) in the text from (A4). Use the envelope theorem to obtain

$$
\frac{\partial V_{t+1}\left(S_{t+1}\right)}{\partial S_{t+1}}=\frac{\partial F_{t+1}\left(S_{t+1}\right)}{\partial S_{t+1}}=\alpha_{t+2}(1+\mu)^{-1} E_{t+1}\left(\frac{\partial V_{t+2}\left(S_{t+2}\right)}{\partial S_{t+2}} \frac{\partial S_{t+2}}{\partial S_{t+1}}\right)+\lambda_{t+1} .
$$

Noting that $\partial S_{t+2} / \partial S_{t+1}=1,($ A8) implies

$$
E_{t}\left(\frac{\partial V_{t+1}\left(S_{t+1}\right)}{\partial S_{t+1}}\right)=\alpha_{t+2}(1+\mu)^{-1} E_{t}\left(E_{t+1}\left(\frac{\partial V_{t+2}\left(S_{t+2}\right)}{\partial S_{t+2}}\right)\right)+E_{t}\left(\lambda_{t+1}\right) .
$$

With (A4) we can obtain

$$
E_{t+1}\left(\frac{\partial V_{t+2}\left(S_{t+2}\right)}{\partial S_{t+2}}\right)=\frac{(1+\mu)}{\alpha_{t+2}}\left(B_{Q}\left(Q_{t+1}, u_{t+1}\right)-\lambda_{t+1}\right) .
$$


Combine (A4), (A9) and (A10) to obtain

$$
\frac{(1+\mu)}{\alpha_{t+1}}\left(B_{Q}\left(Q_{t}, u_{t}\right)-\lambda_{t}\right)=\alpha_{t+2}(1+\mu)^{-1} E_{t}\left(\frac{(1+\mu)}{\alpha_{t+2}}\left(B_{Q}\left(Q_{t+1}, u_{t+1}\right)-\lambda_{t+1}\right)\right)+E_{t}\left(\lambda_{t+1}\right)
$$

which simplifies to

$$
B_{Q}\left(Q_{t}, u_{t}\right)=\lambda_{t}+\alpha_{t+1}(1+\mu)^{-1} E_{t}\left(B_{Q}\left(Q_{t+1}, u_{t+1}\right)\right)
$$

(This step makes use of the fact that $E_{t}\left(E_{t+k}\left(x_{t+k}\right)\right)=E_{t}\left(x_{t+k}\right)$ for $\left.k \geq 1\right)$. Since a competitive permit market equilibrium in a period requires $B_{Q}\left(Q_{t}, u_{t}\right)=p_{t},(\mathrm{~A} 11)$ implies

$$
p_{t}=\lambda_{t}+\alpha_{t+1}(1+\mu)^{-1} E_{t}\left(p_{t+1}\right)
$$

Iterating (A12) to $n$ periods ahead yields:

$$
\begin{aligned}
p_{t} & =\lambda_{t}+\alpha_{t+1}(1+\mu)^{-1} E_{t}\left(p_{t+1}\right) \\
& =\lambda_{t}+\alpha_{t+1}(1+\mu)^{-1} E_{t}\left(\lambda_{t+1}+\alpha_{t+2}(1+\mu)^{-1} E_{t+1}\left(p_{t+2}\right)\right) \\
& =\lambda_{t}+\alpha_{t+1}(1+\mu)^{-1} E_{t}\left(\lambda_{t+1}\right)+\alpha_{t+1} \alpha_{t+2}(1+\mu)^{-2} E_{t}\left(p_{t+2}\right) \\
& =\lambda_{t}+\alpha_{t+1}(1+\mu)^{-1} E_{t}\left(\lambda_{t+1}\right)+\alpha_{t+1} \alpha_{t+2}(1+\mu)^{-2} E_{t}\left(\lambda_{t+2}+\alpha_{t+3}(1+\mu)^{-1} E_{t+2}\left(p_{t+3}\right)\right) \\
& =\lambda_{t}+\alpha_{t+1}(1+\mu)^{-1} E_{t}\left(\lambda_{t+1}\right)+\alpha_{t+1} \alpha_{t+2}(1+\mu)^{-2} E_{t}\left(\lambda_{t+2}\right)+\alpha_{t+1} \alpha_{t+2} \alpha_{t+3}(1+\mu)^{-3} E_{t}\left(p_{t+3}\right) \\
& \vdots \\
& =\lambda_{t}+\sum_{s=1}^{n-1}\left(\prod_{s} \alpha_{t+s}(1+\mu)^{-s} E_{t}\left(\lambda_{t+s}\right)\right)+\prod_{s=1}^{n} \alpha_{t+s}(1+\mu)^{-n} E_{t}\left(p_{t+n}\right),
\end{aligned}
$$

which is equation (3) in the text. 


\section{References}

Burtraw, Dallas, Karen Palmer, and Danny Kahn. 2010. “A symmetric safety valve.” Energy Policy 38(9), 4921-4932.

Cason, Timothy N., Steven R. Elliott and Mark R. van Boening. 1999. "Speculation in experimental markets for emissions permits." Research in Experimental Economics 7, Charles Holt and R. Mark Isaac (eds). Stamford. Conn: JAI Press.

Cason, Timothy N. and Lata Gangadharan. 2006. "Emissions variability in tradable permit markets with imperfect enforcement and banking." Journal of Economic Behavior and Organization 61(2), 199-216.

Cronshaw, Mark, and Jamie Brown Kruse. 1996. "Regulated firms in pollution permit markets with banking," Journal of Regulatory Economics 9(2), 179-189.

Fell, Harrison and Richard Morgenstern. 2010. "Alternative approaches to cost containment in a cap-and-trade system." Environmental and Resource Economics 47(2), 275-297.

Fell, Harrison, Erica Moore and Richard Morgenstern. 2011. "Cost containment under cap and trade: a review of the literature." International Review of Environmental and Resource Economics 5, 285-307.

Fell, Harrison, Dallas Burtraw, Richard Morgenstern, and Karen Palmer. 2012. "Soft and hard price collars in a cap-and-trade system: A comparative analysis." Journal of Environmental Economics and Management 64(2), 183-198.

Godby, Robert W., Stuart, Mestelman, R. Andrew Muller, and J. Douglas Welland . 1997. "Emissions trading with shares and coupons when control over discharges is uncertain." Journal of Environmental Economics and Management 32(3), 359-381.

Grull, Georg and Luca Taschini. 2011. "Cap-and trade properties under different hybrid scheme designs.” Journal of Environmental Economics and Management 61(1), 107-118.

Hood, Christina. 2010. "Reviewing existing and proposed emissions trading systems." International Energy Agency Information Paper. OECD/IEA.

Isaac, R. Mark and Charles Plott. 1981. "Price controls and the behavior of auction markets: an experimental examination." American Economic Review 71(3), 448-459.

Jacoby, Henry D. and A. Denny Ellerman. 2004. “The safety valve and climate policy.” Energy Policy 32(4), 481-491. 
Kling, Catherine and Jonathan Rubin. 1997. "Bankable permits for the control of environmental pollution." Journal of Public Economics 64(1), 101-115.

Muller, R. Andrew and Stuart Mestelman. 1998. "What have we learned from emission trading experiments?" Managerial and Decision Economics 19(4-5), 225-238.

Murray, Brian C., Richard G. Newell and William A. Pizer. 2009. "Balancing cost and emissions certainty: an allowance reserve for cap-and-trade." Review of Environmental Economics and Policy 3(1), 84-103.

Newell, Richard G., William A. Pizer, and Daniel Raimi. 2013. "Carbon markets 15 years after Kyoto: lessons learned, new challenges." Journal of Economic Perspectives 27(1), 123-146.

Nordhaus, William D. 2007. "To tax or not to tax: alternative approaches to slowing global warming." Review of Environmental Economics and Policy 1(1), 26-44.

Perkis, David F., Timothy N. Cason, and Wallace E. Tyner. 2012. “An experimental investigation of hard and soft price ceilings in emissions permit markets." Paper prepared for presented at the Agricultural \& Applied Economics Association's 2012 AAEA Annual Meeting, Seattle, Washington, August 12-14, 2012.

Philibert, Cédric. 2008. "Price caps and price floors in climate policy: A quantitative assessment.” International Energy Agency Information Paper. OECD/IEA.

Pizer, William A. 2002. "Combining price and quantity controls to mitigate global climate change." Journal of Public Economics 85(3), 409-434.

Pizer, William A. 2005. "Climate policy design under uncertainty." Resources for the Future Discussion Paper 05-44.

Roberts, M.J. and M. Spence. 1976. "Effluent charges and licenses under uncertainty," Journal of Public Economics 5(3-4), 193-208.

Rubin, Jonathan. 1996. "A model of intertemporal emissions trading, banking, and borrowing." Journal of Environmental Economics and Management 31(3), 269-286.

Schennach, Susanne. 2000. "The economics of pollution permit banking in the context of Title IV of the 1990 Clean Air Act Amendments." Journal of Environmental Economics and Management 40(3), 189-210.

Smith, Vernon L., and Arlington W. Williams. 1981. "On nonbinding price controls in a competitive market." American Economic Review 71(3), 467-474. 
Smith, Vernon L., and Arlington W. Williams. 2008. Effect of nonbinding price controls in double auction trading." Handbook of Experimental Economics Results, Charles Plott and Vernon Smith (eds.). Amsterdam: North Holland, 2008, 46-53.

Stranlund, John K., James J. Murphy, and John M. Spraggon. 2011. “An experimental analysis of compliance in dynamic emissions markets.” Journal of Environmental Economics and Management 62(3), 414-429.

Stranlund, John K., and L. Joe Moffitt. 2013. "Enforcement and price controls in emissions trading." Journal of Environmental Economics and Management 67(1), 20-38.

Weber, Thomas A., and Karsten Neuhoff. 2010. "Carbon markets and technological innovation." Journal of Environmental Economics and Management 60(2), 115-132.

Webster, Mort, Ian Sue Wing, and Lisa Jakobovits. 2010. "Second-best instruments for nearterm climate policy: Intensity targets vs. the safety valve." Journal of Environmental Economics and Management 59(3), 250-259.

Zhao, Jinhua, 2003. "Irreversible abatement investment under cost uncertainties: tradable emission permits and emissions charges." Journal of Public Economics 87(12), 2765-2789. 